\title{
Environmental Stupidity
}

\author{
James F Welles*
}

East Marion, USA

ISSN: 2637-8078

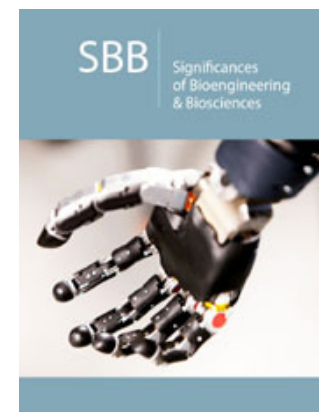

*Corresponding author: James F Welles, East Marion, USA

Submission: 侮 March 18, 2020

Published: 觜 March 20, 2020

Volume 4 - Issue 1

How to cite this article: James F Welles. Environmental Stupidity. Significances Bioeng Biosci.4(1). SBB.000577.2020. DOI: 10.31031/SBB.2020.04.000577

Copyright@ James F Welles, This article is distributed under the terms of the Creative Commons Attribution 4.0 International License, which permits unrestricted use and redistribution provided that the original author and source are credited.

\section{Opinion}

The relationship of America to its natural environment is parasitic if not suicidal. However, we have surprisingly few illusions about ourselves being anything but exploiters, as we simultaneously rape, strangle and poison our life support system. Eventually, such behavior will limit our development, and we are actually has-tening that day in that we have elevated exploitation to something of a cultural virtue.

While struggles in the fields of politics and social relations dominated the post-war consciousness, there gradually grew in the background an awareness of the ominous strain the burgeoning human population is putting on the world's limited resources. Earth Days notwithstanding, this awareness remains largely the property of environmentalists [1] while political power remains in the hands of industrialists who are willing victims of the neurotic paradox. In the pursuit of immediate profits, they are dedicated to the irresponsible exploitation of nature's resources and seem determined to top all the stupidity of all ages past combined with a grandiose display of pollution [2] and destruction of the natural world that supports them. To this end, they have thus far succeeded in keeping the government officials who should be monitoring their nefarious activities happily mired down in their own self-constructed restrictive rules, regulations and red tape.

With industry dedicated to the immediate ravaging of the environment, some kind of international birth control policy limiting the quantity of human life must be implemented if any kind of quality of life is to be sustained over the long haul. For what it is worth, which is not much, the Catholic Church's position on the population problem is consistent with the idea that the miracle of the loaves and fishes can be repeated endlessly [3]. This is the position of Norman Burloug, who looked to science for salvation through genetically engineered crops which yield endlessly greater harvests. On the other hand, William Vogt viewed such activities as merely setting up a more extensive crash when we finally reach the carry capacity of the world [4]. For skeptics, another non-growth strategy is very much in order if not much in evidence.

One strategy that has to go is the obsolete growth and development syndrome [5]. With the earth's resources already apparently stretched to the limit, we simply cannot sustain continued growth of the human population [6], particularly if it is bent on maintaining the current standard of living while wrecking its support system, as it currently is. However, a new philosophy of self-limitations is going to be difficult to formulate, could not be imposed on an unenlightened public and will probably be accepted only after we finally become ashamed of how much enduring misery we can create and the world can maintain or maybe when it ceases to be perceived as profitable to the mighty.

The greatest stupidity of all is that we have made our own plight difficult and are making it impossible with overpopulation, pollution and the exploitation of non-renewable resources. There are some encouraging signs that these problems are finally being recognized as such by people in positions of power, although too little is being done about them. Thus, a stupid person has an advantage in coping with this world over one who tries to understand it logically, as it is a world of compromises, tradeoffs and shabby political charades pulled off by self-seeking 
hacks using ideas and abusing ideals to suit their seedy needs and sordid purposes. The surprise is not that it does not make any sense but that anyone with any brains ever believed it could.

There are two factors which are crucial to the systematic desecration of the environment:

A. The organization and mobilization of people for the task.

B. The development of machinery to facilitate the process. Our population is well suited in both quantity and quality to wrecking the environment in that there are too many of us committed to a standard of living beyond the carrying capacity of God that is, to a standard which is attainable for the entire population for only a limited period of time [7].

In addition, there is specialization and division of labor in our attack on the environment: those not actively engaged in ravaging the land usually devote their energies to polluting the air and water. All this is done in the name of profit and for the sake of bigger and costlier possessions for as many people as possible. Sadly, the ultimate limits for population growth will be determined not by reasoned planning but by the efficiency with which we can poison our support system and convert our urban centers into behavioral sewers.

To accelerate this process of social suicide, we have turned to machines and computers. The guiding maxim is that the world must be made safe for technology. The worst part of this trend is not that we are ever more efficient at wrecking the environment but that we are bent on creating a world in which machines rather than people can thrive. To the extent that we become robots, we will fit into the world we are creating. However, our success in adapting will be a function of our willingness to renounce the differences between humanity and cybernity. Civilization has developed to the mutually interactive point that we now have to become less human as we adapt to the self-effacing technology which creates us.

\section{References}

1. Read R (2008) Is there still a role for the state?

2. Hawking S (2018) Pollution and stupidity remain our most challenging problems.

3. Pitkin WB (1932) A short introduction to the history of human stupidity. Simon and Schuster, USA, p. 512.

4. Mann C (2019) The wizard and the prophet. Knopf Doubleday Publishing Group, New York, USA.

5. Hammond P (1978) An introduction to cultural and social anthropology $\left(2^{\text {nd }} e d n\right)$, Macmillan Publishers, New York, USA, p. 141.

6. Brown L (1994) State of the world. In: World may be at biological limit as growth in food supplies slows. Associated Press, New York, USA, p. 10A.

7. Pimental D, Harman R, Pacenza M, Pecarsky J, Pimentel M (1994) Natural resources and an optimum human population. Population and Environment 15(5): 347-369. 